\title{
VOJSKA Z VIDIKA TEMELJNIH POJMOV SOCIALNE PSIHOLOGIJE
}

\section{MILITARY FROM THE POINT OF VIEW OF BASIC SOCIAL PSYCHOLOGY TERMS}

Povzetek Namen tega prispevka je predstaviti temeljne pojme socialne psihologije in z njimi na podlagi izkušenj, pridobljenih v Slovenski vojski, pogledati vojaško organizacijo. Vojska je organizacija, v kateri ima skupina večji pomen kot posameznik. Pogled na vojaško organizacijo prek temeljnih pojmov socialne psihologije se zdi logičen korak, ki lahko prinese uporabna nova spoznanja za obe področji, tako za socialno psihologijo kot za vojaški sistem. Povezava je izpeljana na podlagi izkušenj, pridobljenih z delom v Slovenski vojski.

V prvem delu so predstavljeni temeljni koncepti socialne kognicije: teorije pozornosti in kognitivnih shem, stereotipi, stališča in teorija pripisovanja. V drugem delu sledijo temeljni koncepti, vezani na skupino, kot so interakcija znotraj skupine s procesi posnemanja, sugestije, identifikacije in socialnega pritiska, ter koncept socialne moči.

V zadnjem delu z uporabo teh pojmov orišemo vojaško organizacijo, natančneje Slovensko vojsko, in sicer njeno hierarhično ureditev, policentrično in asimetrično razporeditev moči ter prepletanje formalne in neformalne moči v njenem vsakodnevnem delovanju.

Ključne besede

Abstract

\section{Vojska, socialna psihologija, socialna kognicija, skupina.}

The aim of this article is to present basic concepts of social psychology and to take a closer look at a military organization based on the experiences gained within the Slovenian Armed Forces.

In military organizations, the group is of greater importance than the individual. A closer look at a military organization through the prism of those basic social psychology concepts seems like a logical step that can lead to useful new knowledge in, both, social psychology and the military system. The link between the two is derived on the basis of experience acquired through the employment in the Slovenian Armed Forces. 
The first part of the article focuses on basic concepts of social cognition, such as the theories of attention, cognitive schemas, stereotypes, attitudes and theories of attribution.

In the second part of the article we focus on basic concepts related to groups, such as interaction with the processes of imitation, suggestion, identification, social pressure and the concepts of social power,

In the last part we use these key concepts to illustrate a military organization, notably the Slovenian Armed Forces, its hierarchical structure, polycentric and asymmetric distribution of power and the intertwining of formal and informal power in its daily routine.

\section{Key words Military, social psychology, social cognition, group.}

Uvod Namen tega prispevka je predstaviti temeljne koncepte socialne psihologije in poskusiti opisati njihovo aplikativno vrednost za vojaški sistem. V vojaški organizaciji je nosilec večine nalog vojaška enota, ne glede na to, ali gre za naloge v miru, za klasične bojne naloge ali mirovne operacije.

Dobro delovanje enote je torej za vojaški sistem ključnega pomena, saj povečuje verjetnost uspešno opravljene naloge. Vojska je organizacija, v kateri ima skupina, torej vojaška enota, večji pomen kot posameznik.

Predpostavimo, da poznavanje procesov, ki vplivajo na medosebno interakcijo in jo določajo, ter poznavanje skupinskih procesov znotraj skupine in med skupinami pripomoreta $\mathrm{k}$ boljšemu delovanju skupine, in da je skupina oziroma enota temeljna celica, ki v vojaškem sistemu opravlja naloge. Iz naštetega lahko sklepamo, da poznavanje dognanj socialne psihologije lahko pripomore k večji učinkovitosti vojaškega sistema.

\section{SOCIALNA KOGNICIJA}

Podlaga za delovanja posameznika v socialnem okolju so procesi zaznavanja in predelave informacij. V socialnem kontekstu jih opredeljujemo z imenom socialna kognicija. M. D. Lieberman navaja (v prostem prevodu): »To, kdo smo kot ljudje, je v veliki meri povezano s tem, kar se dogaja med našimi ušesi. To, kar se dogaja med našimi ušesi, je močno povezano s socialnim svetom, znotraj katerega potujemo, smo v njem aktivni in se nanj odzivamo.« (2010, str 143) Povedano drugače, nihče od nas ni v vakuumu, vsi smo del nekega okolja. Dogajanje zunaj je povezano z dogajanjem znotraj nas. Vse skupaj pa določa, kdo kot posameznik smo. Ljudje smo nenehno izpostavljeni toku informacij, ki izvirajo iz nas in okolja. Informacij, $\mathrm{s}$ katerimi se v tem okolju srečujemo, ne sprejemamo samodejno in naivno kot npr. kamera ali diktafon, prav tako jih ne prenesemo v naš spomin neposredno, nespremenjenih in točno takšnih, kot so bile sprejete v zaznavnem sistemu (Hamilton, 2005). Pri njihovem prenosu in predelavi pri človeku sodeluje več procesov, eden pomembnejših, ki služi kot podlaga drugim, je pozornost. 


\subsection{Pozornost}

S pozornostjo se ukvarjajo predvsem raziskovalci s področja kognitivne psihologije in širšega področja kognitivnih znanosti.

Definirati, kaj je pozornost, je za psihologijo še vedno težava. V zgodovini psihologije je bilo več različnih definicij ali opredelitev, kaj pozornost je. Tako na primer James (1890, po Styles, 2006) pravi, da je vsem jasno, kaj je pozornost, in se vsebine ne dotika. Shiffrin (1988, po Styles 2006) pravi, da je pozornost uporabljena za vse vidike človeških zaznav, ki jih lahko posameznik nadzoruje in so povezane z omejenimi zmogljivostmi in sredstvi človeškega zaznavanja. Pashler (1999) pa v knjigi Psychology of attention zapiše, da za svoje izhodišče jemlje predpostavko, da nihče ne ve, kaj je pozornost.

Kljub težavam z definicijo obstaja splošen konsenz, da je pozornost povezana z omejenostjo človeškega zaznavnega aparata in njegovih procesov (Styles, 2006).

Človekov zaznavni aparat je končen, ima svoje omejitve. Tako smo na primer omejeni pri razponu tonov, ki jih lahko zaznamo, ali pa z valovno dolžino svetlobe, na katero se odzivajo naši čuti. Tudi če ostanemo znotraj omejitev, ki jih imajo naša čutila, je »informacij v vsakem trenutku v okolju več, kot jih človekov zaznavni aparat lahko predela« (Ule, 2009; Styles, 2006). S procesi pozornosti naš zaznavni aparat opravlja funkcijo »vratarja« (Hamilton, 2005). Nikoli ne moremo biti pozorni na vse, kar se dogaja v našem okolju. Bolj ko je to okolje bogato, več je informacij, ki se »borijo« za vstop v našo zavest. Ker pa lahko zavestno obdelamo le omejeno količino podatkov, potrebujemo filter, ki to količino zmanjša. Vlogo tega filtra ima pozornost. Procesi pozornosti, s katerimi filtriramo podatke, potekajo tako z zavestnim usmerjanjem kot tudi samodejno (Styles, 2006). To, da so nekateri procesi samodejni, pomeni, da imamo svojo pozornost le delno pod nadzorom volje. Tako lahko dražljaji večje moči (npr. glasen pok, močan blisk) samodejno pritegnejo našo pozornost, tudi če smo jo zavestno usmerjali drugam (npr. v pogovor, opazovanje neke osebe itn.).

Socialno okolje je informacijsko zelo bogato, kot rečeno pa smo pri količini podatkov, ki jih lahko hkrati predelujemo, omejeni. To pomeni, da obstaja velika verjetnost, da nam bodo nekatere informacije tudi ušle. Seveda pa niso vsi podatki enako pomembni. Tako je na primer za voznika podatek, da na semaforju gori rdeča luč, pomembnejši kot ta, katera pesem se vrti po radiu. Za vojaka je podatek, da je v bližini glasno počilo, pomembnejši od tega, da se nadrejeni pogovarja z njim. Uspešnost naše interakcije z okoljem je močno odvisna od tega, ali je naša pozornost usmerjena na prave, ključne informacije, ali so »filtri« v določeni situaciji torej »pravilno nastavljeni«.

Našo pozornost vodi in usmerja kognitivni aparat (Hamilton, 2005), še posebej pomembno vlogo pri njenem usmerjanju pa imajo kognitivne sheme. 


\subsection{Kategorizacija in kognitivne sheme}

Bruner (2005) navaja, da zaznava inherentno vsebuje akt kategorizacije. Vse, kar zaznavamo, uvrščamo v kategorije. Kategorizacija pomeni razvrščanje dogodkov, stvari in dražljajev v skupine oziroma kategorije (Ule, 2009), ki so lahko zelo široke. Tako lahko na primer predmete uvrstimo v kategorijo nevarnih ali nenevarnih. Lahko pa so kategorije zelo specifične, kot na primer opazovanje silhuet letal in njihovo razvrščanje v posebne podkategorije po vrstah letal. Šele v procesu kategorizacije objekti in dogodki dobijo svoj pomen (Hamilton, 2005). Dokler dražljaja ne kategoriziramo, ostaja za nas neznanka.

Kategorije vodijo do kompleksnejših struktur, ki jih imenujemo kognitivne sheme. Kognitivne sheme so abstraktne strukture znanja, zgrajene na pridobljenih dražljajih, ki zagotavljajo ciljno usmerjeno obdelavo informacij (Thorndyke, 1979; po White in Carlston, 1983). Vse, kar ljudje zaznavamo, poskušamo povezati v smiselne celote oziroma strukture, ki nam nato pomagajo pri zaznavanju novih dražljajev. S kognitivnimi shemami si osmislimo svet, ki nas obdaja. Pogosto nam že ustvarjene kognitivne sheme pomagajo določiti, kateri elementi oziroma informacije so bolj in katere manj pomembne. Temu ustrezno usmerjamo tudi našo pozornost. Tako kot za pozornost tudi za kognitivne sheme velja, da lahko ti procesi potekajo zavestno ali samodejno, torej ne da bi se jih neposredno zavedali. Na splošno velja, da pozornost usmerjamo na informacije, ki so najbolj pomembne (Kenarick in Petersen; po White in Carlston, 1983). Toda katere so najbolj pomembne in po katerih merilih to določimo? V socialni situaciji so to informacije, ki lahko neko shemo ali pričakovanje potrdijo ali ovržejo (Bower, Black in Turner; po White in Carlston, 1983), in informacije, ki še niso uvrščene v sheme (White in Carlston, 1983). Povedano drugače, v neki situaciji smo najprej pozorni na stvari, ki pomagajo določiti, ali je situacija skladna z našimi pričakovanji ali ne. Za primer si lahko predstavljamo vojaka, ki je zamenjal enoto. Ob prihodu v novo enoto bo pozoren na stvari, ki mu bodo povedale, kako se ta enota razlikuje od njegove prejšnje. Ali se postrojitvena pravila izvajajo enako ali pa so vseeno opazne razlike. Ali je na primer pozdravljanje $\mathrm{z}$ roko dosledno $\mathrm{v}$ rabi ali pa je mogoče sprejemljivo tudi pozdravljanje samo $\mathrm{z}$ glasom. Na podlagi zaznanega bo vojak prilagodil svoje vedenje.

Še posebej pa smo v novi situaciji pozorni na elemente, ki so nam neznani. Neznanka v okolju pomeni morebitno nevarnost.

Ljudje smo nagnjeni $\mathrm{k}$ temu, da nove informacije prilagajamo obstoječim shemam (Ule, 2009), v okolju iščemo informacije, ki se ujemajo z našimi shemami. Ko neko situacijo uvrstimo v shemo, smo bolj pozorni na informacije, ki to prepričanje potrjujejo, tiste ki niso skladne s prepričanji, pa poskušamo prilagoditi oziroma uskladiti (White in Carlston, 1983).

Sheme nam ne služijo le pri določanju ključnih informacij, uporabljamo jih tudi za dopolnjevanje manjkajočih. Kot smo že napisali, smo ljudje omejeni pri tem, koliko podatkov lahko v določenem času obdelamo. To pomeni, da se pogosto znajdemo $\mathrm{v}$ 
položaju, ko ne moremo biti pozorni na vse, kar se okoli nas dogaja. Še več, dogaja se, da nam uidejo pomembne informacije. Da je tega čim manj, si pomagamo tudi s kognitivnimi shemami. Na podlagi pričakovanj, ki izhajajo iz naših shem, informacijske praznine zapolnjujemo $\mathrm{z}$ informacijami iz sheme, ki smiselno pokriva to situacijo (Hamilton, 2005).

Vse povedano velja tudi v socialnem kontekstu in v socialnih zaznavah. Sheme, pozornost, zaznavanje in predelava informacij, vse to je prisotno, ko presojamo druge ljudi, sebe, odnose, skupine, skratka socialni svet okoli nas. Pomembno pa je tudi zavedanje, da ti procesi potekajo tudi pri drugih. Tudi drugi presojajo nas, naše odnose, našo skupino, enoto.

Poveljnik oddelka ima oblikovane vsaj nekatere sheme o svoji enoti, vojakih in nadrejenih, enako verjetno velja za vojake in njihove sheme o poveljniku oddelka in oddelku.

Vojaška enota je tako prostor, znotraj katerega se srečuje množica individualnih predstav, pričakovanj in predvidevanj, ki se navezujejo na enoto in njene pripadnike, pa tudi na širšo strukturo, znotraj katere je enota.

Tako se lahko znotraj majhne enote, kot je oddelek, pojavljajo zelo različne kognitivne sheme dobrega vojaka, dobrega poveljnika, dobrega oddelka. To pomeni, da pripadniki znotraj majhne enote nekatere stvari vidijo zelo različno. To je povezano tako z razlikami v tem, katere so ključne informacije, in tem, kam posameznik usmerja svojo pozornost. Zelo pomembno je tudi, kako posamezniki zapolnijo informacijske vrzeli, ki so posledica omejitev pozornosti.

Kognitivne sheme nas v večini primerov privedejo do pravilnih sklepov. Brez tega se verjetno ne bi obdržale (Hamilton, 2005). Imajo pa tudi svoje pomanjkljivosti, zaradi katerih smo ljudje nagnjeni tudi k postavljanju napačnih sklepov oziroma napakam. Tako se lahko informacijske vrzeli napačno zapolnijo. Pogoste napake tako nastanejo na podlagi sklepanja iz stereotipov.

\subsection{Stereotipi}

Stereotipe lahko opredelimo kot podkategorijo kognitivnih shem. To so generalizirane povezave neke skupine lastnosti s celotno skupino ljudi (Ule, 2009, Dijksterhuis, 2010). Tako je lahko stereotipna predstava o vojaku nastala zato, ker se osebi $\mathrm{v}$ vojaški uniformi pripisujejo lastnosti, ki nimajo stvarne podlage, pa naj bodo to negativne lastnosti, kot je agresivnost, ali pozitivne, kot je lojalnost ali pogum.

Ustvarjanje stereotipov in uvrščanje vanje je v bistvu nezaveden proces (Dijksterhuis, 2010), kar pomeni, da so stereotipi zunaj našega zavestnega nadzora in da sami zelo težko vemo, kdaj so prisotni. 
Dunning in Sherman (1997) v svojih študijah odkrivata, da imajo generalizirane stereotipne predstave vpliv tudi na vedenje pri posameznikih, ki na zavestni ravni te stereotipe zavračajo. Kar pomeni, da lahko nekatere predstave deklarativno tudi zelo iskreno zavračamo, vendar naše vedenje kaže, da so te predstave v globljih, zavesti manj dostopnih strukturah še vedno prisotne. In kar je še pomembneje, na naše vedenje imajo močnejši vpliv kot naša zavestna prepričanja.

Vedenje, skladno z našimi stereotipnimi pričakovanji, lahko ima še dodatno pomembno posledico, saj lahko zares spodbudi stereotipno vedenje pri ciljni osebi (Dijksterhuis, 2010). Pričakovanje agresivnega vedenja pri nekom lahko povzroči naše agresivno vedenje, kar privede do agresivnega odziva in s tem do potrditve stereotipa, ki pa smo jo izsilili sami. Ljudje smo nagnjeni k temu, da vzdržujemo naše kognitivne sheme (Ule, 2009) in z njimi tudi naše stereotipe. To pomeni, da so stereotipi strukture, ki jih težko spreminjamo. Sheme se spremenijo ali prilagodijo le, ko so informacije dovolj močne in jih ni mogoče prilagoditi že obstoječim strukturam in tem strukturam celo nasprotujejo (Ule, 2009; Hamilton, 2005).

Sklepanje na podlagi stereotipov ima lahko zelo nevarne posledice. Več raziskav (Correl, Park, Judd in Wittenbrink, 2002) je pokazalo, kako lahko rasni stereotip nevarno vpliva na zaznavo in vedenje posameznika ali množice v posebni situaciji. V različnih simuliranih situacijah so pokazali, da je veliko večja verjetnost, da pri temnopoltem moškem, ki ima v roki orodje ali telefon, izurjeni opazovalci ta nenevarni objekt zamenjajo z orožjem. Zato je večja verjetnost, da se na temnopoltega moškega opazovalec odzove kot na nevarnega posameznika.

Mednarodno delovanje in večkulturni prostor sta postala stalnica, znotraj katere delujejo sodobne vojaške organizacije, tudi Slovenska vojska v tem ni izjema, saj deluje $\mathrm{v}$ mednarodnih poveljstvih in na mednarodnih misijah v kulturno zelo raznolikih okoljih. Za ta okolja je značilna kulturna, etnična, religiozna in spolna heterogenost. Prav tako najdemo podobno heterogenost tudi znotraj vojske. To je prostor, v katerem se lahko razvijejo in uveljavijo stereotipi.

\subsection{Stališča}

Tesno povezana s kognitivnimi shemami in stereotipi so stališča. Po Uletovi (2009) so stališča socialno pridobljene strukture. Zanje ni bioloških predispozicij. Definicij stališč je preveč (Banaji in Heiphetz, 2010), da bi jih v tem besedilu obravnavali. Relativno soglasje pa vlada okoli njihovega jedrnega elementa - vrednotenja (Banaji in Heiphetz, 2010). Crano in Prislin (2006; po Banaji in Heiphetz, 2010, str. 357) zapišeta, da so »/.../ stališča, vrednostne sodbe, ki združujejo in povzemajo /.../ kognitivne oziroma afektivne reakcije.« Poenostavljeno lahko rečemo, da so stališča naš »za« in naš »proti«.

Po klasičnih teorijah imajo stališča tri komponente: afektivno (čustva), kognitivno (prepričanje) in konativno (vedenje) (Banaji in Heiphetz, 2010). Sodobne teorije poudarjajo afektivno komponento kot tisto, ki prevlada nad drugima dvema (Banaji in 
Heiphetz, 2010). Bila naj bi lažje in hitreje dosegljiva kot kognitivna. Iz tega bi lahko sklepali, da ljudje nismo nujno racionalna bitja. Lavine, Thomsen, Zanna in Borgida (1998, po Banaji in Heiphetz, 2010) za predsedniške volitve v ZDA ugotavljajo, da so v primerih, ko so prepričanja in čustva v nasprotju, čustva boljši napovedovalec vedenja. Pri oblikovanju »za« ali »proti« imajo torej čustva pri ljudeh večji vpliv kot zaznave.

V povezavi stališč in socialnega presojanja se je pokazalo, da je v ospredju uporaba dveh dimenzij - dobrote oziroma topline (prijaznosti) in kompetenc (sposobnosti) (Banaji in Heiphetz, 2010). V ozadju pa je prepričanje, ki ga podpirajo empirični dokazi (Banaji in Heiphetz, 2010), da socialna interakcija zahteva odgovore na dve temeljni vprašanji. Prvo je, kako dober je človek, dober ali slab, meni naklonjen ali ne, drugo vprašanje pa je, kako kompetenten je ta človek oziroma kako učinkovit je v tem, kar dela. Odgovori na prvo vprašanje so hitreje dosegljivi (Banaji in Heiphetz, 2010) in imajo tudi večji vpliv na ustvarjanje stališč in naše vedenje.

Podobne dimenzije so se pokazale kot koristne tudi za delo v vojaški skupini (Malone, 2003). Ključni informaciji, ki ju potrebujemo za oceno vojaka (ne glede na čin) in njegov prispevek vojaški enoti, sta, kako motiviran je (ali je dober ali slab) in kako je usposobljen oziroma ali je kompetenten.

Če sledimo povedanemu, tudi v tem primeru velja, da je čustvena komponenta (ali je nekdo prijateljski ali sovražen, ali sodeluje ali ne) lažje dosegljiva in s tem pomembnejša kot kognitivna.

Tesno povezano s socialno presojo, kaj človek hoče in kaj zna oziroma zmore, je tudi pripisovanje vzrokov oziroma teorija pripisovanja (Hamilton, 2005).

\subsection{Teorija pripisovanja (atribucije)}

Teorija pripisovanja spada v področje tako imenovane naivne psihologije (Ule, 2009, Hamilton, 2005). Ljudje v svojem vsakdanjem življenju in medsebojnih stikih pripisujemo dogodkom okoli sebe različne vzročne povezave, osebam pripisujemo odgovornost za njihovo vedenje. Od tega, kako osebi pripišemo odgovornost za njeno vedenje, je odvisno, ali jo sprejemamo, nam je simpatična, ali pa jo zavračamo (Ule, 2009).

Procesi pripisovanja so tesno povezani s socialnimi zaznavami (Ule, 2009, Hamilton 2005). Heider (2005) je navedel na pomembno ločnico, ki se veže na vzročni vir. Nekateri vzroki za dejanja in vedenje so notranji, izhajajo iz človeka (osebnostne poteze, motivi, stališča itn.), drugi pa so zunanji, izhajajo torej iz okolja (socialni pritisk, situacijske omejitve in zahteve itn.).

Ljudje smo kot opazovalci pri pripisovanju odgovornosti pristranski (Hamilton, 2005). Ross (1977, po Hamilton, 2005) poroča o »izvorni napaki pripisovanja«. Pri presojanju vedenja drugih ljudi so opazovalci nagnjeni k precenjevanju notranjih 
vzrokov (motivov, osebnostnih potez itn.), hkrati pa so zelo »imuni« za prepoznavanje moči zunanjih dejavnikov, ki lahko vplivajo na vedenje v neki situaciji ali ga celo določajo. Poznejše študije so pokazale (Menon 1999; po Hamilton 2005, str. 286), da je »izvirna napaka pripisovanja« kulturno pogojena. V evropsko-ameriškem kulturnem krogu opazovalci pripisujejo vzroke vedenja notranjim vzrokom posameznika, v vzhodnoazijskem pa opazovalci vzroke vedenja bolj pripisujejo vplivom skupine.

\section{SKUPINA IN NJENE ZNAČILNOSTI}

\subsection{Značilnosti skupine oziroma vojaške organizacije}

Za socialno psihologijo je skupina temeljno področje raziskovanja, zato so se številni avtorji osredotočali na iskanje definicij posameznih značilnosti in notranje dinamike skupine. Metodološko so nekateri, kot npr. Krech in Crutchfield (1948; po Zvoneriviču 1985), uporabili interakcijo med posameznimi pripadniki za definiranje značilnosti skupine, drugi, npr. Cattel (1951; po Zvonariviču 1985), pa so se pri svojih definicijah osredotočali na funkcionalnost skupine v smislu zadovoljevanja potreb njenih članov. Bili so tudi poskusi združevanja obeh definicij (Gibb, 1954; po Zvonarevič, 1985). Na splošno v socialni psihologiji skupino pojmujemo kot zbir posameznikov, med katerimi obstaja interakcija, zaradi katere se vedenje in aktivnost posameznika spreminjata zaradi prisotnosti drugih članov skupine. Ob tem je treba poudariti, da fizična prisotnost drugih članov ni nujna (ni pogoj za oblikovanje skupine), ampak zadošča že zavest o pripadnosti skupini.

Sodobnejše teorije (Levine, 2006) govorijo o skupinskosti kot kontinuumu, ki se razteza med ekstremoma od neskupinskosti do skupine. Skupine torej ne obravnavajo kot ali je ali ni, temveč poskušajo skupino ljudi uvrstiti v kontinuum po tem, koliko je skupinskost pri njih izražena.

Za obravnavo skupine znotraj vojaškega sistema je pomembno, kar je o skupini poudaril Stogdill (1950; po Zvonarevič, 1985), in sicer, da gre pri tem za vprašanje prisotnosti vodje. Kadar imamo skupino s stalno prisotnim vodjo in definirane razlike v odgovornosti pri doseganju ciljev - oboje pa je v vojaškem okolju nepogrešljivo - skupino obravnavamo kot organizacijo. Takšno razlikovanje temelji na neenakomerni porazdelitvi socialne moči med posamezniki znotraj skupine oziroma organizacije.

\subsection{Interakcija znotraj skupine}

Če je socialna moč ločnica med skupino in organizacijo, nas zanimajo tudi pogoji, ki ustvarjajo socialno moč znotraj organizacije. Predvsem je to proces interakcije, ki se nanaša na vzajemno delovanje posameznikov znotraj skupine. Interakcija poteka tako v primeru, ko je posameznik v resnici obdan z drugimi člani skupine (prostorska bližina) ali pa se jih le zaveda (psihološka bližina), neredko pa sta sočasno prisotni obe. 
Med različnimi avtorji, ki so se posvečali vprašanju interakcije, sicer prihaja do nekaterih razlik pri določanju njenih posameznih mehanizmov, splošno sprejemljivi pa obsegajo elemente (glej npr. Zvonarevič, 1985):

a) posnemanje (imitacija) - predpostavlja se obstoj modela, ki služi kot vzor, in posnemovalcev, ki lahko zavedno (hote) ali nezavedno (nehote, samodejno) posnemajo vedenje modela. Posnemanje velja za najmanj naporen način učenja, v ozadju deluje težnja po konformizmu. Iz prakse so v vojaški organizaciji znani primeri, da podrejeni posnema nadrejenega v vedenju, govoru, telesni drži ipd.;

b) sugestija - podobna posnemanju, le da pri sugestiji model izvaja pritisk na sprejemnika (posnemovalca), od njegove dovzetnosti pa je odvisno, kako bo od modela prevzel zamisel, ki včasih tudi ni zadovoljivo argumentirana;

c) identifikacija se pojavlja, ko model v očeh posnemovalca uživa ugled oziroma avtoriteto. Z identifikacijo posnemovalec na videz povečuje tudi svojo pomembnost. Identifikacija z drugimi člani oziroma skupino in njenimi cilji se lahko pojavi tudi, če posameznik postane član skupine mimo svoje volje ali celo v nasprotju z njo (naborniki v sistemu obveznega služenja vojaškega roka, mobiliziranci itn.);

d) simpatija in antipatija - dva pola istega mehanizma. Gre za čustveno kategorijo, ki se prav zaradi tega lahko izrazi brez potrebnih razumskih omejitev, kar ima lahko močan vpliv na posameznika ali na vso socialno interakcijo v skupini;

e) socialni pritisk - gre za mehanizem, ko se v skupini vzpostavi vzdušje, ki članom skupine vzbuja občutek nevarnosti, če ne spoštujejo predpisanih pravil. Socialni pritisk skupina izvaja s sredstvi prepričevanja (prošnja, nasvet, priporočilo) ali sredstvi prisile (nagrada, obljuba, grožnja, kazen). Socialni pritisk vsekakor srečamo tudi v skupinah v vojaškem okolju, saj je lahko za skupino oziroma njene pripadnike zelo nevarno, če v kritičnih trenutkih pri doseganju skupnega cilja ne sodelujejo vsi člani. Žal se lahko pojavijo tudi negativni vidiki, ko zaradi socialnega pritiska skupine tudi tisti posamezniki, ki sicer tega ne bi storili, začnejo kazati različne oblike vedenja, ki niso v skladu z vojaškim pravom (npr. kruto ravnanje z vojnimi ujetniki in civilisti itn.). Kot ena ostrejših kazni v vojaških skupinah je znan bojkot, saj lahko posameznika, proti kateremu je usmerjen, razmeroma močno ogroža. Vojaške skupine oziroma enote se namreč neredko znajdejo v položajih, v katerih je medsebojna pomoč življenjsko pomembna;

f) inhibicija in facilitacija - gre za pojav, ko se zaradi prisotnosti drugih članov skupine aktivnost posameznika poslabša (zavre) ali izboljša (pospeši), pri čemer sploh ni nujno, da so preostali člani fizično prisotni. Mehanizem lahko deluje tudi, ko je posameznik v popolni fizični izolaciji, vendar pa kljub temu čuti psihično povezanost $\mathrm{z}$ drugimi člani in pripadnost skupini. Ta mehanizem $\mathrm{v}$ vojaškem okolju na primer pride do izraza, ko se vojaški ujetnik kljub ostremu 
zasliševanju ne zlomi, ampak mu občutek pripadnosti pomaga, da vzdrži tudi v položaju, ki ogroža njegovo življenje.

\subsection{Velikost in trajanje skupine}

Ob vprašanju prisotnosti drugih članov skupine in njihovem vplivu na vedenje posameznika je zelo pomembna tudi velikost skupine. Čim večja je skupina, tem močnejši je njen vpliv. Socialna psihologija govori o majhnih in velikih skupinah, kar ustrezaprevedeno v vojaško terminologijo - majhnim in velikim enotam v vojaški organizaciji. V razmerah vojaških spopadov je odločitev o tem, kako velika bo skupina, ki se angažira za izvršitev neke naloge, pač pogojena z objektivnim dejstvom - nasprotnikovo močjo. Še vedno pa velja Southova (1927; po Zvonerivič, 1985) ugotovitev, da so manjše skupine uspešnejše pri reševanju konkretnih vprašanj, večje pa pri spoprijemanju z abstraktnimi. South (prav tam) razlaga, da ima za konkretno vprašanje ali težavo vsak član že pripravljeno strategijo rešitve, majhno število članov pa ob tem pomeni krajši čas usklajevanja. Obratno pa je pri abstraktnih težavah ali vprašanjih uspešnejša velika skupina, saj je po zakonu verjetnosti večja možnost, da bo med večjim številom pripadnikov nekdo hitro našel ustrezno rešitev.

Velikost skupine pomembno vpliva na vodenje. Bales (1953; po Zvonarevič, 1985) je ugotovil, da se v skupinah, ki štejejo do pet pripadnikov, vodja sporazumeva $\mathrm{z}$ njimi kot s posamezniki, v večjih pa se nanje obrača kot na skupino.

Hemphill (1950; po Zvonarevič, 1985) pa je odkril, da so v skupinah, ki so štele največ trideset ljudi - v vojski je to velikost voda - zahteve do vodje manjše kot $\mathrm{v}$ večjih skupinah.

Skupine seveda lahko delujejo različno dolgo, zato moramo upoštevati tudi ta vidik. Delovaje nekaterih je kratkotrajno, kar pomeni, da delujejo le, dokler ni dosežen kratkoročni cilj, nato pa se ukinejo. $Z$ vojaškega vidika pa so bolj zanimive skupine, ki delujejo več časa, mednje spadajo standardne vojaške enote. Njihov cilj - zagotavljanje varnosti - je dolgoročen, skorajda trajen, zato so tudi same dolgotrajne. V mnogih vojskah imajo enote, ki so bistveno starejše od njihovih članov. Zanje velja, da preživijo številne generacije pripadnikov, ki se v njih zvrstijo. Skladno s tem se razvije tradicija, ki še dodatno utrjuje stabilnost skupine, ta pa je po mnenju mnogih avtorjev v pozitivni povezavi z njeno trajnostjo. Treba pa je upoštevati tudi, da se članstvo v teh skupinah pogosto menja, kar praviloma negativno vpliva na stabilnost.

V civilnem okolju najdemo podobnost v navijaških skupinah, v katerih se pri podpori nekemu športnemu klubu zvrsti več generacij članov.

\subsection{Socialna struktura}

Skupina ima svojo psihosocialno strukturo, tako horizontalno kot vertikalno. To pomeni, da se v vertikalni strukturi izraža hierarhija posameznih vlog in statusov, horizontalna struktura pa obsega posamezne podskupine, ki imajo enak status. 
V vojaških enotah je vertikalna struktura še posebno izražena in jasno formalizirana. $\mathrm{Na}$ vertikalno strukturo se veže pojav socialne stratifikacije, kar je vzrok nastanka podskupin, ki nimajo enakega socialnega statusa. Razlike izvirajo iz vloge, ki jo ima posameznik (podskupina) znotraj skupine. Višje ko je hierarhično mesto (vloga), ki ga posameznik (podskupina) zaseda, večjo možnosti vplivanja na aktivnosti in na preostale člane ima. Razlike med vlogami same po sebi niso vprašljive, saj so nujne za normalen razvoj skupnosti.

V zvezi s strukturo moramo osvetliti dva pomembna pojma, in sicer socialno distanco in socialno mobilnost. Socialna distanca je razlika v statusu med dvema posameznikoma ali socialnima podskupinama in kot takšna izvor morebitnih konfliktov, izvira pa iz različnih vlog in s tem povezane neenakomerne porazdelitve socialne moči. Lahko je vzrok konfrontacij med hierarhično višjimi, ki skušajo svoj privilegirani status obdržati, in tistimi, ki so na hierarhični lestvici nižje in bi radi položaj spremenili ali vsaj zmanjšali distanco.

Kot je bilo že rečeno, so v vojaških enotah ravno zaradi formaliziranosti vertikalne strukture vsi obravnavani pojmi še toliko bolj izraziti. Za vojsko je značilen sistem činov, ki so zunanji znak položaja posameznika v hierarhiji in s tem povezanega vpliva, ki ga ima ta na aktivnosti v skupini in na druge člane. Prav tako je v vojaškem okolju zaradi te formaliziranosti dobro opazna tudi socialna mobilnost, to je možnost spremembe socialnega statusa znotraj skupine. Obstaja institucionaliziran sistem napredovanja, po katerem posameznik ob izpolnjevanju vnaprej določenih pogojev napreduje po hierarhični lestvici, s čimer poleg materialnih ugodnosti pridobiva tudi na socialnem statusu. Socialna mobilnost in distanca sta tudi v medsebojni povezavi, manjša ko je socialna distanca, manjša je tudi težnja po socialni mobilnosti.

$\mathrm{Na}$ socialno strukturo se navezujeta še pojma formalne in neformalne skupine. $\mathrm{V}$ formalni skupini, v primerjavi z neformalno, so vloge in nanje vezana pričakovanja eksplicitno definirani. $Z$ vidika razvoja skupine se pogosto dogaja, da se najprej oblikuje neformalna skupina, ko pa struktura postane trajnejša in stabilnejša, se pojavi težnja $v$ smeri formalizacije. $Z$ vidika socialne dinamike je pomembno izpostaviti, da v okviru neke širše skupine, na primer tudi vojaške enote, lahko sočasno delujejo formalne in neformalne skupine, ki nastanejo kot rezultat različnih socialnih interakcij. Načeloma ta pojav sam po sebi ni vprašljiv, težave pa je pričakovati, če si neformalne skupine poskušajo prisvojiti vlogo formalnih, pri čemer bi prišlo do redistribucije socialne moči.

\subsection{Socialna moč}

Socialna moč je izraz, ki ga pogosto uporabljamo, tako v vsakdanjem pogovornem jeziku kot v strokovni terminologiji. Različne definicije, ki ga poskušajo strokovno opredeliti, se osredotočajo na različne vidike. Tako Lasswel in Kaplan (1950; po Zvonarevič, 1985) socialno moč vidita v sodelovanju pri odločanju, Schulze (1956; po Zvonarevič, 1985) pa meni, da je socialna moč potencial oziroma zmožnost 
člana skupine vplivati na preostale posameznike znotraj skupine. Drugi avtorji (Weber, 1946, Tannenbaum, 1968, Haer, 1963; po Zvonarevič, 1985) poskušajo razlagati socialno moč z uvajanjem pojmov, kot so volja, nadzor, akcija, determiniranje. Zvonarevič (1985) predlaga definicijo: »Socialna moč je sposobnost posameznikov, skupin ali organizacij (centri socialne moči), da vplivajo na aktivnosti in vedenje drugih posameznikov, skupin ali organizacij.« Čeprav je definicija na videz zelo preprosta, skriva $\mathrm{v}$ sebi pomembne elemente za raziskovanje socialne moči.

a) Centri socialne moči

Mednje spadajo posamezniki, skupine in organizacije, ki imajo poseben vpliv in jih na podlagi različnih meril delimo na:

- formalne in neformalne centre, pri čemer je za formalne značilno, da delujejo skladno z normativnimi pravnimi akti (ustava, zakon, statut, pravilnik, direktiva, ukaz itn.), medtem ko neformalni delujejo mimo takšnih normativov ali celo $\mathrm{v}$ nasprotju $\mathrm{z}$ njimi. $\mathrm{Z}$ vidika legalnosti so torej formalni centri moči vedno legalni, za neformalne pa to ne velja, zato so aktivnosti neformalnih skupin pogosto prikrite širši javnosti. Ni si težko predstavljati, da v vojaškem okolju dejavnosti neformalnih centrov moči privedejo do večjih ali manjših motenj pri doseganju cilja;

- individualni in kolektivni centri, pri katerih je merilo zelo jasno, ali gre za eno osebo (predsednik, premier, direktor, poveljnik itn.) ali več posameznikov (predsedstvo, komisija, odbor, senat itn.). Med individualnimi in kolektivnimi centri obstajajo pomembne razlike, predvsem v vodenju in odgovornosti, kar je tudi razlog, da vojska temelji na individualnih;

- nominalni in realni centri - nominalni naj bi navidezno imeli moč, realni pa je v resnici imajo. $\mathrm{V}$ vojaških enotah je za normalno delovanje nujno, da so nominalni centri v resnici tudi realni. Nasprotno bi namreč pomenilo, da enote ne vodi njen poveljnik, temveč nek neformalni in obenem realni vir moči, kar pa je v vojaškem okolju nesprejemljivo;

- notranji in zunanji centri - kot je mogoče sklepati že iz poimenovanja, imamo opraviti z jedri, ki delujejo znotraj oziroma zunaj skupine, na katero vplivajo. Tudi v tem primeru velja, da je za vojaške enote sprejemljiv edino obstoj notranjih virov moči. V nasprotnem, če se namreč v vodenje enote poskušajo vmešavati zunanji neformalni dejavniki, ki pa imajo realno moč, upravičeno pričakujemo motnje v normalnem delovanju. Takšnim poskusom so lahko zaradi svojega bolj ali manj naključnega oblikovanja izpostavljene začasne enote, navadno namenjene izvršitvi ene same, točno določene (tudi časovno) naloge. Primer tega so kontingenti v mirovnih operacijah v tujini, kjer se pripadniki na eni strani srečujejo s formalnim, realnim in notranjim centrom socialne moči, ki ga predstavlja poveljniška linija kontingenta, obenem pa ne morejo prezreti zunanjih, neformalnih, pa vendar realnih centrov, delujočih v okolju, od koder prihajajo in kamor se navadno vračajo, če bi se ti v resnici poskušali uveljavljati. 
b) Distribucija socialne moči

Distribucija socialne moči je izjemno pomemben dejavnik, saj ne vpliva le na medsebojne odnose med posameznimi centri, temveč pogojuje celotno socialno klimo v skupini (enoti), v kateri poteka. Lahko je monocentrična, kar pomeni, da je vsa moč v rokah enega centra, če pa jih je več, govorimo o policentrični distribuciji. Če imamo opraviti s policentrično distribucijo moči, se srečamo s pojmom hierarhije centrov moči, ki točno določa, kdo je komu nadrejen ali podrejen. S tega vidika izhaja, da se v vojaškem okolju srečujemo z monocentrično in tudi s policentrično distribucijo socialne moči, odvisno pač, iz katerega zornega kota gledamo. Na ravni temeljne vojaške enote je sprejemljiva le monocentrična distribucija, saj enote ne more voditi vsakdo po malem. Če pa gledamo na vojsko kot celotno institucijo, se nedvomno srečujemo s policentrično distribucijo socialne moči s sočasnim obstojem stroge hierarhije. Ta ne dopušča dvoma, kateri center je kateremu nadrejen, obstaja pa glavni, v katerem se vsi vzvodi moči združujejo.

c) Vpliv

Intenzivnost vpliva niha med dvema skrajnostma: ničelnim vplivom (kadar ga sploh ni zaznati) in maksimalnim (ko ima center možnost odločujočega poseganja). Vpliv je lahko neposreden, usmerjen neposredno na akcijo, ali pa posreden, če poteka prek vmesnega člena (ali poveljujoči neposredno ukazuje ali si pri tem pomaga s poveljujočimi na nižjih ravneh). Različen je tudi njegov obseg, saj ima center moči vpliv na različno število posameznikov ali skupin in tudi na različno število akcij, ki v skupini potekajo (v vojaškem okolju je obseg vpliva določen s hierarhično stopnjo, na kateri je center). Center, ki ima možnost vplivanja, lahko svoj potencial uresniči, v tem primeru govorimo o aktualnosti vpliva, ali pa tudi ne. Odvisno od tega, ali gre za individualni ali skupinski center moči, se srečujemo z individualnim ali skupinskim vplivom (v vojski skupinski vpliv redkeje najdemo, npr. odločitve, ki jih sprejemajo različne komisije, veliko pogosteje se srečujemo z individualnim vplivom).

Vplivi se med seboj, poleg drugega, ločujejo po trajnosti. Trajen vpliv imajo tisti centri moči, ki so tudi sami trajni, lahko trajajo tudi dlje od življenja posameznika. Obratno pa govorimo o kratkotrajnem vplivanju, kadar centri moči svoj potencial uporabljajo le občasno.

Legalnost vpliva se povezuje $\mathrm{z}$ delitvijo centrov socialne moči na formalne in neformalne. Formalni centri svoj vpliv uresničujejo legalno, vpliv neformalnih centrov pa je lahko ilegalen, pollegalen ali celo nelegalen (npr. klientelizem, nepotizem itn.) in kot tak škodljiv, pa naj gre za skupine v civilnem okolju ali vojaške enote.

č) Akcija oziroma aktivnost

Akcije se med seboj razlikujejo glede na pomembnost, vsebino, načrtovanost in individualnost.

Pomembnost akcije je njeno najmočnejše orodje, saj je z njo določena količina socialnega vpliva, ki se uveljavi. Vsaka akcija ima svojo vsebino, določeno s 
področjem, na katerem poteka. Ker lahko registriramo izjemno veliko število področij, bi temu primerno lahko govorili tudi o zelo velikem številu vsebin. V praksi pa se navadno omenjajo ekonomske, politične, kulturne in zdravstvene vsebine, z vojaškega vidika so za nas zanimive vsebine, ki bi jih opredelili kot varnostne.

Naslednja značilnost akcije je njena načrtovanost ali nenačrtovanost. Večina akcij je načrtovanih, nekatere pa so spontane. Delitev na načrtovane in spontane je smiselna, ker je vpliv centrov socialne moči pri načrtovanih veliko bolj izražen kot pri nenačrtovanih. Ne nazadnje, akcije delimo na individualne, pri katerih deluje le en pripadnik skupine, in na kolektivne, pri katerih sodeluje skupina.

e) Količina socialne moči

Količina socialne moči je resnični pokazatelj pomembnosti centra socialne moči, odvisna pa je od dveh elementov: pomembnosti akcije, na katero ta center vpliva, in intenzivnosti vpliva. Iz tega sklepamo, da ima veliko socialno moč posameznik ali skupina (center socialne moči), ki intenzivno vpliva na pomembne akcije. Obratno velja, da center z manjšo socialno močjo vpliva na manj pomembne akcije, pa še to malo.

Kot je bilo že rečeno, se v vojaškem okolju srečujemo s policentričnim sistemom distribucije socialne moči, pri čemer so posamezni centri med seboj v jasnem hierarhičnem razmerju. Za vse velja, da imajo načeloma najbolj intenziven vpliv, razlika med njimi pa je, da vplivajo na različno pomembne akcije, pač skladno s svojim položajem v hierarhiji.

\section{SLOVENSKA VOJSKA Z VIDIKA TEMELJNIH POJMOV SOCIALNE PSIHOLOGIJE}

Do zdaj smo skušali osvetliti temeljne pojme, ki jih uporablja socialna psihologija. V naslednjem poglavju pa želimo s temi pojmi razložiti nekatere vidike delovanja vojske in vojaške skupine.

\subsection{Metodologija}

Za podlago služijo izkušnje in spoznanja, ki sledijo iz dela psihologa v Slovenski vojski, saj sta avtorja kot enotovna psihologa spremljala več enot, tako doma kot na mednarodnih misijah, predvsem načrtno z analizo psihosocialne klime.

Analiza psihosocialne klime v enotah Slovenske vojske redno poteka, doma enkrat do dvakrat na leto, odvisno od nalog in potreb, za enote na misijah pa vsaj dvakrat v pol leta. Praviloma je v dveh delih, podlaga zanjo pa so enotni vprašalniki, namenjeni notranji uporabi. Z vprašalniki poskušamo izmeriti te sklope: horizontalna kohezivnost (zaupanje in razumevanje med pripadniki na isti ravni v enoti), vertikalna kohezivnost (zaupanje in razumevanje med poveljujočimi in podrejenimi), kakovost prenosa informacij (jasnost in pravočasnost informacij za opravljanje naloge) in način zagotavljanja standardov (način uporabe nagrad in kazni ter zadovoljstvo z 
uveljavljenimi standardi). Na vprašalnike navadno odgovarjajo vsi pripadniki enote, na podlagi rezultatov vprašalnika pa se opravijo še pogovori z njimi (ločeno vojaki in poveljujoči).

Kot dodaten vir informacij služijo tudi druge oblike spremljanja enot in njihovih pripadnikov. To so tako formalni in neformalni pogovori s pripadniki, sodelovanje na poveljniških sestankih in terenskih usposabljanjih ter udeležba na mednarodnih misijah.

Ko se lotimo z vidika temeljnih pojmov socialne psihologije pogledati nekatere vidike delovanja vojske in vojaške skupine v Slovenski vojski, je treba razlikovati med dvema vidikoma: vojsko kot institucijo in vojaško enoto.

\subsection{Vojska kot institucija}

Glede na to, da je vojska skupina s stalno prisotnim vodjo in jasno definiranimi razlikami v odgovornosti pri doseganju ciljev, smo upravičeni sklepati, da je skupina prerasla v organizacijo. Znotraj te (vojaške) organizacije opažamo neenakomerno porazdelitev socialne moči med posamezniki ali podskupinami (centri socialne moči). Socialna moč se razširja policentrično, pri čemer je očitna stroga hierarhija med posameznimi centri. Hierarhija je obenem izvir vpliva centrov - višje ko so na hierarhični lestvici, večji je njihov vpliv. Tako je znotraj vojaške organizacije jasno, da je poveljnik čete nad poveljnikom voda in da je poveljnik brigade tisti, katerega moč velja za vso brigado, medtem ko moč poveljnika polka velja le za del te brigade.

Slovenska vojska je razmeroma velika in trajna organizacija, saj je namenjena doseganju trajnega cilja (varnost države pred zunanjim sovražnikom in naravnimi nesrečami). Centri socialne moči so praviloma formalni, individualni (poveljniška odgovornost) in notranji. Uniformiranost in jasne oznake služijo temu, da lahko kdor koli v organizaciji prepozna vlogo in socialno moč drugega pripadnika, tudi če je ta zanj popolnoma neznan. Hkrati pa v Slovenski vojski velja načelo enostarešinstva, kar pomeni, poveljuje lahko le eden. Hkrati s hierarhično ureditvijo to pomeni, da je na vrhu vsake piramide (voda, brigade vojske) le en poveljujoči. Nominalni centri morajo biti obenem tudi realni centri socialne moči.

Kot za vse skupine tudi za vojsko velja, da je znotraj nje nenehno prisotna interakcija med posamezniki ali podskupinami. Interakcija poteka tako v okoliščinah prostorske (posameznik je obdan z drugimi pripadniki) kot psihološke bližine (drugi pripadniki fizično niso prisotni).

Od interakcijskih mehanizmov v vojski srečujemo praktično vse tiste, ki jih socialna psihologija pozna tudi sicer: posnemanje, sugestijo, identifikacijo, socialni pritisk ter inhibicijo oziroma facilitacijo. 
Posnemanje je prisotno v vseh vidikih, je pa praviloma izrazitejše v mlajših enotah, pri pripadnikih, ki vstopajo v sistem. Pravilna izbira modela in uspešno sledenje sta podlaga za dobro vključevanje $\mathrm{v}$ enoto.

Identifikacija je značilnejša za enote na višji stopnji delovanja. Pripadniki ponotranjijo standarde in norme skupine. V vlogi prototipa in hkrati osebe avtoritete pa je poveljujoči. Nevarno za enoto lahko postane, če kot objekt identifikacije služi pripadnik, ki nasprotuje formalni strukturi vodenja.

Socialni pritisk se v vojaških enotah pojavlja v različnih oblikah. Prisotne so formalne oblike, na primer predpisane sankcije za odklonsko vedenje. V nekaterih enotah se pojavlja socialni pritisk kot del bolj ali manj neformalnih iniciacijskih procesov, ki spremljajo vključevanje novega pripadnika v enoto. Primeri so lahko obvezna uporaba posebej določenih tobačnih izdelkov, ki služijo kot znak pripadnosti enoti, rizične aktivnosti, s katerimi se dokazuje lojalnost enoti, in doseganje nadstandardov usposobljenosti. Iz primerov je razvidno, da so lahko posledice socialnega pritiska v vojaški enoti tako pozitivne kot negativne oziroma škodljive. Pri usmerjanju socialnega pritiska in njegovem obvladovanju ima veliko vlogo poveljniška struktura.

Socialna struktura v vojski je jasno določena, kar še posebej velja za vertikalno strukturo, ki je formalizirana tudi s sistemom činov, temelji pa na hierarhični lestvici. $\mathrm{S}$ tem se pojavljata socialna distanca in $\mathrm{z}$ njo povezana socialna mobilnost, ki poteka znotraj institucionaliziranega sistema napredovanja. Kljub temu pa se v vojaških sistemih vzpostavlja tudi neformalna socialna struktura, ki lahko podpira formalno ali pa ji nasprotuje. Tako ima lahko navaden vojak, ki sicer nima formalne moči, zaradi svojih izkušenj in znanja v enoti velik vpliv. Dobri poveljujoči temu vplivu praviloma ne nasprotujejo, temveč ga v svojem delovanju uporabijo kot podporo. V nekaterih primerih pa se nasprotovanje med formalno in neformalno strukturo izrazi kot upor podrejenih poveljujočim. Če se to zgodi, je lahko delovanje vojaške enote zelo okrnjeno. Na bojišču so lahko posledica tega žrtve, do katerih sicer ne bi prišlo.

\subsection{Vojaška enota}

Če želimo osvetliti skupinske dinamične mehanizme v vojaških enotah v ožjem pomenu besede, se pojavi vprašanje, kaj sploh je osnovna enota v Slovenski vojski. Publikacija Navodilo - lahka pehotna (motorizirana) četa jasno navaja, da je četa osnovni in najpomembnejši del organizacije in temelji na podlagi sprejete kadrovske in materialne formacije. Zato nam bo ravno četa služila kot referenčni okvir za osvetlitev skupinskih dinamičnih mehanizmov v vojaški enoti. Četo lahko uvrstimo med velike skupine, saj ima na primer pehotna četa okoli 120 pripadnikov. Tudi druge čete imajo praviloma več kot 60 pripadnikov. So pa sestavljene iz manjših enot, vodov in oddelkov, ki jih lahko uvrščamo že v sklop majhnih skupin. Vod, kot največja med njimi, šteje približno 30 pripadnikov.

V četi obstaja policentrični sistem distribucije socialne moči. Poveljujoči na četni ravni je hierarhično najvišji in ima kot posameznik odločilen vpliv na podrejenega 
poveljnika voda, ta pa na poveljnika oddelka. Vsi ti centri socialne moči so formalni in notranji. Prav tako so vsi nominalni ter obenem realni. Sočasno delovanje neformalnih centrov ni nujno kontraproduktivno, če njihov vpliv ni v nasprotju z aktivnostjo formalnega centra.

Prisotni so enaki mehanizmi socialne interakcije kot v vojski kot celoti, tudi socialna distanca ter težnja po socialni mobilnosti. Pojavlja se fluktuacija članstva, del tega je posledica izstopa nekaterih pripadnikov (upokojitev, menjava zaposlitve) in zaposlovanja novih. Pripadniki krožijo tudi po različnih dolžnostih znotraj Slovenske vojske. Kroženje po sistemu jim omogoča nabiranje izkušenj in znanja, ki bi bilo sicer zanje težje dosegljivo. Del fluktuacije je tako posledica tega, da pripadniki z novim znanjem in novimi kompetencami napredujejo tudi vertikalno. Fluktuacija pa ima lahko tudi negativen vpliv, če je preveč intenzivna. Neprestana menjava članstva pomeni, da se lahko zaupanje v preostale pripadnike enote gradi le na formalni podlagi. Predvsem za manjše enote (vod, tudi četa) pa se kaže, da je za dobro delovanje enote nujno zaupanje, pridobljeno na osebni izkušnji (skupno delo na terenu, uspešno opravljene naloge itn.) Prevelika fluktuacija onemogoča, da bi znotraj enote potekali procesi, v katerih enota zori in postaja učinkovitejša.

Fluktuacija ima lahko v vojaškem sistemu tudi higiensko vlogo. S pravilnim pretokom pripadnikov se manjša verjetnost, da bi neformalne vloge znotraj enote in s tem neformalni centri moči pridobili večjo moč kot formalni.

V Slovenski vojski se zaradi sorazmerne majhnosti sistema in zastavljenosti kariernih poti dogaja, da je pretočnost poveljniškega kadra večja kot pretočnost vojakov. Občasno se zaradi tega zgodi, da morajo poveljujoči, predvsem v manjših enotah, pokazati več spretnosti pri sodelovanju z nosilci neformalne moči, saj imajo ti, vsaj na začetku, večji pregled nad stanjem in življenjem enote kot poveljujoči.

Glede na to, da so posamezniki v osnovnih vojaških enotah praviloma obdani z drugimi člani, upravičeno govorimo o pojmu prostorske bližine, psihološka bližina pa je temelj občutka pripadnosti enoti. Pripadnost enoti je v resnici tisto, kar si želijo poveljujoči, predvsem tisti, ki se zavedajo, da moč enote ne temelji le na orožju in opremi, temveč predvsem na ljudeh. Izkušnje potrjujejo, da se psihološka bližina gradi s prostorsko bližino, pri čemer pojem prostorske bližine pri vojaški enoti širimo tudi na prostor skupnih izkušenj. Praviloma velja, da imajo enote, katerih pripadniki intenzivneje delijo izkušnjo »biti skupaj« v raznolikih situacijah, tudi intenzivnejši občutek psihološke bližine oziroma pripadnosti. Graditi občutek pripadnosti v različnih izkušnjah pa pomeni, da za to potrebujemo čas. Bolj ko je naloga zahtevna, več ko je pripadnikov enote, ki morajo biti usklajeni, več časa potrebujemo.

Sklep V članku smo poskusili slediti dvema ciljema. Prvi je narediti pregled temeljnih pojmov socialne psihologije, drugi pa s temi pojmi razložiti vojaško organizacijo z vidika izkušenj, pridobljenih v Slovenski vojski. 
Tem ciljem smo uspeli slediti le v omejenem obsegu. Tako na primer ostaja skoraj nedotaknjena tema dinamike majhnih skupin in posebnosti te dinamike v vojaških enotah. Nismo se dotaknili delitve na taktično, organizacijsko in strateško raven znotraj vojaške hierarhije in povezave te delitve s socialno močjo. Nedotaknjena je tema interakcije vojaške organizacije z okoljem, na primer, kako lahko stališča širše javnosti vplivajo na delovanje kontingenta $\mathrm{v}$ mednarodni operaciji.

Prav tako smo le na splošno predstavili spoznanja, ki sledijo iz dela v Slovenski vojski.

Kljub temu upamo, da je članek uspel v tem, da je predstavil nekatere temeljne pojme socialne psihologije in uspešno pokazal na dodano vrednost, ki jo pridobimo, če s teh vidikov pogledamo na vojaško organizacijo.

1. Banaji, M. R., Heiphetz, L., 2010. Attitudes. V S. T. Fiske, D. T. Gilbert, G. Lindzey, ur. Handbook of Social Psychology, Fifth edition, vol.1. New Jersy: Wiley, 2010, str. 353393.

2. Bruner, J. S., 2005. On Perceptual Readiness. VD. L. Hamilton, ur. Social Cognition. New York: Psychology Press. 2005, str. 108-114.

3. Correl, J., Park, B., Judd, C. M., Wittenbrink, B., 2005. The Police Officer 's Dilemma: Using Ethnicity to Disambiguate Potentially threatening Individuals. V D. L. Hamilton, ur. Social Cognition. New York: Psychology Press. 2005, str. 451-469.

4. Dijksterhuis, A., 2010. Automaticity and The Unconcious. V S. T. Fiske, D. T. Gilbert, G. Lindzey, ur. Handbook of Social Psychology, Fifth edition, vol.1. New Jersy: Wiley, 2010, str. 228-267.

5. Dunning, D., Sherman, D. A., 2005. Stereotypes and Tacit Inference. V D. L. Hamilton, ur. Social Cognition. New York: Psychology Press. 2005, str. 48-62.

6. Hamilton, D. L., 2005. Social Cognition. New York: Psychology Press.

7. Heider, F., 2005. The Naive Analysis of Action. V D. L. Hamilton, ur. Social Cognition. New York: Psychology Press. 2005, str. 288-298.

8. Levine, J. M., Moreland, R. L., 2006. Small Groups: An Owerview. V J. M. Levine, R. L. Moreland ur. Small Groups. New York: Psychology Press, 2006, str. 1-32.

9. Lieberman, M. D., 2010. Social cognitive neuroscience. V S. T. Fiske, D. T. Gilbert, G. Lindzey, ur. Handbook of Social Psychology, Fifth edition, vol.1. New Jersy: Wiley, 2010, str. 143-193.

10. Malone, D. M., 2003. Small Unit Leadership: A Commonsense Approach. New York: Balantine Books.

11. Pashler, H. E., 1999. The Psychology of attention. Massachusetts: MIT.

12. Styles, E., 2006. The Psychology of Attention, 2nd edition. New York: Psychology Press.

13. Ule, M., 2009. Socialna psihologija. Analitični pristop k življenju v družbi. Ljubljana: Založba FDV.

14. White, J. D., Sherman, D. A., 2005. Consequences of Shemata for Attention, Impressions, and Recall in Complex Social Interactions. V D. L. Hamilton, ur. Social Cognition. New York: Psychology Press. 2005, str. 36-47.

15. Zvonarevič, M., 1985. Socialna psihologija. Zagreb: Školska knjiga. 